\title{
Oxidation of electrodeposited cobalt electrodes in an alkaline electrolyte
}

\author{
M. Grdeń • J. Jagiełto
}

Received: 9 June 2012 /Revised: 9 August 2012 / Accepted: 28 August 2012 / Published online: 18 September 2012

(C) The Author(s) 2012. This article is published with open access at Springerlink.com

\begin{abstract}
The oxidation of electrodeposited Co electrodes has been studied in $0.1 \mathrm{M} \mathrm{KOH}_{\mathrm{aq}}$ at potentials more negative than $-880 \mathrm{mV}$ vs. $\mathrm{Hg} \mid \mathrm{HgO}$ by means of electrochemical quartz crystal microbalance (EQCM) and rotating ring disk electrode coupled with cyclic voltammetry (CV) and chronoamperometry (CA). Dissolution of cobalt was found to be insignificant and does not constitute a step in the overall process of formation of the oxidised layer. The irreversibility of the oxidation process depends on the electrode potential and oxidation time. The composition of the oxidised layer depends on the oxidation potential: $\mathrm{Co}(\mathrm{OH})_{2}$ is formed at more negative potentials, while at more positive potentials $\mathrm{CoO}$ is the prevailing product. The results obtained by means of three techniques (CV, CA and EQCM) reveal that at potentials not higher than $-880 \mathrm{mV}$, the oxidation of Co follows a direct logarithmic law. The mechanism of the process is discussed.
\end{abstract}

Keywords Cobalt $\cdot$ Electrochemical quartz crystal microbalance $(\mathrm{EQCM}) \cdot$ Metal oxidation

\section{Introduction}

Recent experiments conducted on noble metal electrodes [1-3] show that the process of surface electrooxidation can be divided into two basic steps: (1) the early stages of formation of the oxidised layer up to ca. one monolayer and (2) further thickening of the oxidised layer. Each of these stages proceeds according to a different mechanism. It

M. Grdeń $(\bowtie) \cdot$ J. Jagiełło

Faculty of Chemistry, University of Warsaw,

Pasteura 1,

02-093 Warsaw, Poland

e-mail: mgrden@chem.uw.edu.pl was found that the early stages of electrochemical formation of a surface oxide/hydroxide of noble [1-6] and some of nonnoble metals [7] can be described by the direct logarithmic law. This law predicts a linear relationship between the amount of the oxidised layer formed, in thickness or charge units, and the logarithm from the oxidation time. The origin of the direct logarithmic law was discussed in the literature and respective mathematical models have been derived $[4,6,8]$. These models, however, have not been applied widely and were used for the analysis of only a few electrochemical systems. Full understanding of the problem requires extension of kinetic studies to non-noble electrodes. Interestingly, the direct logarithmic law is applicable also for nonelectrochemical oxidation of metals [9-11], e.g. cobalt [12].

The process of oxidation of noble metals is usually reversible [1-5], and their solubility in various aqueous media is very often insignificant $[13,14]$. For these metals, the amount of the oxidised layer formed can be easily determined from the measurements of charge of its reduction. The situation becomes more complex for non-noble metals due to the irreversibility of the oxidation process, i.e. formation of hardly reducible layers, and often significant contribution from dissolution of the electrode material. Lack of reliable methods of real surface area determination for many of non-noble metals further complicates the studies.

Cobalt has been selected as a subject of studies on the applicability of direct logarithmic law for oxidation of nonnoble electrodes. The surface of Co can be easily oxidised when in contact with moisture or air $[12,15]$. Despite its numerous applications [16-19], the mechanism of the early stages of Co oxidation in aqueous alkaline solutions has not been studied extensively. Most works focus instead on the composition of Co oxidation products. For potentials more negative than $-500 \mathrm{mV}$ vs. $\mathrm{Hg} \mid \mathrm{HgO}$, the proposed products include $\mathrm{CoO}$ [20-24], hydrated $\mathrm{CoO}$ [25] or various forms of $\mathrm{Co}(\mathrm{OH})_{2}$ [20-24, 26-32]. 
An analysis of polarisation curves for Co oxidation in $1 \mathrm{M} \mathrm{NaOH}$ reveals that the process follows nucleation and growth mechanism with transfer of the first electron as the rate-determining step [31]. In [33], Co oxidation at potentials more negative than $-330 \mathrm{mV}$ vs. $\mathrm{Ag} \mid \mathrm{AgCl}$ was studied in 0.1 and $1 \mathrm{M} \mathrm{NaOH}$ by means of rotating ring disk electrode (RRDE), scanning electrochemical microscopy and atomic force microscopy. Although some dissolution of the electrode was detected, it was concluded that Co oxidation is predominated by a solid state reaction. It was also pointed out that the oxidised layer is formed in a 3D scheme rather than in a layer-by-layer manner. On the other hand, formation of 2D structures during early stages of oxidation of Co single crystals in $0.1 \mathrm{M} \mathrm{NaOH}$ was reported in [29] on the basis of STM measurements. A solid state pathway of formation of $\mathrm{Co}$ (II) layer was also proposed in [22] for $0.2-8 \mathrm{M} \mathrm{KOH}$ with dissolution predominantly of $\mathrm{Co}(\mathrm{OH})_{2}$ rather than metallic cobalt.

Cobalt dissolution is observed in alkaline solutions at potentials as negative as $-850 \mathrm{mV}$ vs. $\mathrm{Hg} \mid \mathrm{HgO}[20,22$, $23,33-37$ ] and depends on $\mathrm{pH}$ [20]. It is not clear, however, whether the dissolution is a step in the overall process of $\mathrm{Co}$ (II) layer formation or a side reaction only [22, 25, 33]. Further complications in studies of Co oxidation are related to the irreversibility of the process caused by an extended Co dissolution or by the formation of a hardly reducible oxidised layer [23, 34-36]. Such irreversibility complicates the application of Co oxidation charges in determination of the real surface area [38], as was already discussed in [34].

In this paper, we report the results of studies on early stages of oxidation of electrodeposited cobalt electrode to Co(II) compounds in $0.1 \mathrm{M} \mathrm{KOH}_{\mathrm{aq}}$. The necessity of application of methods allowing the evaluation of Co solubility (RRDE), reversibility of oxidation process and simultaneous determination of mass changes (electrochemical quartz crystal microbalance, EQCM) leads to selection of electrodeposited Co layers as subject of the studies rather than massive cobalt. The mechanism of the process was evaluated on the basis of chronoamperometric, cyclic voltammetry and EQCM results. We focused on potential range where thin oxidised layers with thickness below the monolayer are formed. The composition of the oxidised layer was determined on the basis of EQCM and X-ray photoelectron spectroscopy results.

\section{Experimental}

Co electrodes were prepared by constant potential electrodeposition $(-805 \mathrm{mV})$ from a bath containing $0.6 \mathrm{M}$ $\mathrm{CoSO}_{4} \cdot 7 \mathrm{H}_{2} \mathrm{O}$ (POCh, p.a.), $0.3 \mathrm{M} \mathrm{KCl}$ (Chempur, p.a.) and $0.26 \mathrm{M} \mathrm{H}_{3} \mathrm{BO}_{3}$ (POCh, p.a.) [34], with a Co wire (Johnson Matthey, $99.999 \%$ ) and $\mathrm{Ag} \mid \mathrm{AgCl}$ serving as a counter and as a reference electrode, respectively. Various substrates were used for electrodeposition: Au wire or foil (99.9\%, Mint of Poland, in CV and X-ray photoelectron spectroscopy (XPS) measurements), gold-covered quartz crystals (EQCM measurements) and Pt disk (RRDE experiments). Electrodeposition efficiency, as estimated from EQCM experiments, was ca. $73 \%$ and the thickness of the deposit was in the range of 1,500 atomic layers. A scanning electron microscope (LEO 435 VP) and EDX (Röntec EDR286) analysis showed that the obtained deposits tightly covered the substrate and no elements other than Co were detected; the latter was also confirmed by XPS analysis and will be discussed later.

The obtained Co deposits were examined in a standard three-electrode setup in $0.1 \mathrm{M} \mathrm{KOH}$ aqueous $\mathrm{KOH}$ (POCh, p.a.) solutions. $\mathrm{Hg}|\mathrm{HgO}| 0.1 \mathrm{M}$ and $\mathrm{Pt}$ gauze wire or $\mathrm{Au}$ foil served as reference and counter electrodes, respectively. All potentials in the text are referred to $\mathrm{Hg} \mid \mathrm{HgO}$. All electrolyte solutions were prepared with Millipore water $(18.2 \mathrm{M} \Omega \mathrm{cm})$. The electrolyte was deoxygenated by bubbling $\mathrm{N}_{2}$ (99.999 \%, Air Products) through the solution.

The electrochemical quartz crystal microbalance setup was composed of an EQCM crystal holder and controller (Model 230, Institute of Physical Chemistry, Warsaw, Poland), an EP20A potentiostat (Elpan), an EG20 (Elpan) linear sweep generator (Elpan), a Hewlett-Packard HP53131A universal counter and an Ambex LC-011-1612 ADC/DAC converter [34]. Gold-covered AT-cut $5 \mathrm{MHz}$ quartz crystals (ITR, Poland) were used. EQCM was calibrated by means of $\mathrm{Ag}$ electrodeposition and stripping in $1.5 \mathrm{mM} \mathrm{AgNO}_{3}+0.1 \mathrm{M} \mathrm{HClO}_{4}$.

The rotating ring disk electrode experiment was performed with an AFMT28T (Pine Instruments) Pt-Pt ring-disk electrode with collecting efficiency of $37 \%$, according to the manufacturer's data, and controlled by an AFMSRX modulated speed rotator (Pine Instruments) and a CHI 700C (CHInstruments) bipotentiostat. The electrochemical behaviour of Co layers with the thickness in the range of thousands of atomic layers was found to be generally the same for Pt and Au substrates used for electrodeposition [34].

Ultra-high vacuum XPS measurements were performed in the Institute of Physical Chemistry of Polish Academy of Sciences with an ESCALAB-210 (VG Scientific) apparatus using an Al X-ray gun. After completing the electrochemical experiments, the electrode was dried with $\mathrm{N}_{2}$ stream, placed in a tightly closed glass vial filled with $\mathrm{N}_{2}$ and transported to the XPS measurements facility.

The electrochemical impedance spectroscopy (EIS) measurements were applied to determine the double layer capacitance used for estimation of the real surface area of the electrodes. The experiments were carried out with a CHI660D potentiostat. AC signal in the frequency range 21,000-1 Hz with 5-mV amplitude was applied. The spectra acquisitions were preceded by $40 \mathrm{~s}$ of polarisation at 
potentials of the measurements. The spectra were fitted with Equivcrt software [39].

\section{Results and discussion}

Real surface area determination

The double layer capacitance measurements, by means of EIS, were applied to determine the real surface area of the Co electrodes studied. Co(II) compounds, $\mathrm{CoO}$ and $\mathrm{Co}$ $(\mathrm{OH})_{2}$, possess semiconducting properties [40] and the interfacial capacitance measured at potentials of surface oxidation contains contributions from the double layer capacitance and from the capacitance of these compounds. A separate determination of the double layer capacitance and the capacitance of thin, semiconducting oxides/hydroxides is then required if the capacitance measurements are to be applied to estimate the real surface area. This, however, can be complicated. Further complications are related to the fact that $\mathrm{CoO}$ and $\mathrm{Co}(\mathrm{OH})_{2}$ might differ in respect to semiconducting properties. As a result, the contribution from the capacitance of the oxidised layer might change with its composition. In such a case, tracking of the oxidation kinetics by the interfacial capacitance measurements is complicated. Hence, the capacitance was measured only in the potential range of hydrogen evolution (HER) where the Co surface is reduced $(-1,300 \geq E \geq-1,400 \mathrm{mV})$ without contribution from the capacitance of Co oxides/hydroxides. Examples of admittance spectra are shown in Fig. 1.

The spectra were fitted to the equivalent circuit presented in the top right inset in Fig. 1 [41, 42]. The double layer capacitance is expressed as a constant phase element (CPE) $[43,44]$ Eq. 1:

$Z_{C P E}=Q^{-1}(i \omega)^{-\alpha}$

where $Q$ is the preexponential factor $\left(3.8210^{-5}-4.4210^{-5}\right.$ $\mathrm{s}^{\alpha} \Omega^{-1} \mathrm{~cm}^{2}$, apparently $E$ independent), $\omega$ is angular frequency, $i$ is the imaginary unit and $\alpha$ is an exponential parameter varying from 0 to 1 (the latter for pure capacitance). The obtained values of $\alpha$ were in the range of $0.91-0.92$. The other components of the circuits include ohmic resistance, $R_{\mathrm{ohm}}$, and the charge transfer resistance of HER, $R_{1} . Z_{\mathrm{CPE}}$ was recalculated into the capacitance according to Eq. 2 [44]:

$C_{d l}=\left(Q\left(R_{\text {ohm }}{ }^{-1}+R_{1}^{-1}\right)^{(\alpha-1)}\right)^{1 / a}$

Because $R_{\mathrm{ohm}}<<R_{1}$, the $C_{\mathrm{dl}}$ values in Eq. 2 are determined by $R_{\text {ohm }}$.

The results of the fitting procedure are presented in Fig. 1 as solid lines, with the top left inset showing the calculated

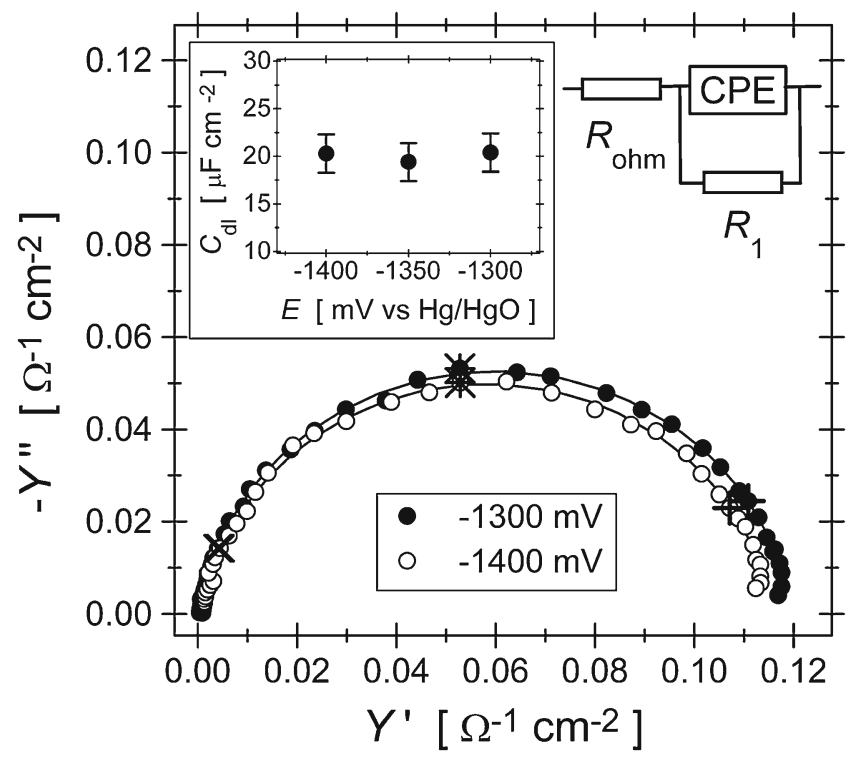

Fig. 1 Examples of impedance spectra recorded for an electrodeposited Co electrode in $0.1 \mathrm{M} \mathrm{KOH}$ at two potentials indicated on the plots and presented in admittance coordinates. Points experimental data, lines fit to the equivalent circuit presented in the right top inset (see details in the text). Points for 4,638.7 Hz (plus sign), $852.5 \mathrm{~Hz}$ (asterisk) and $97.7 \mathrm{~Hz}$ (multiplication symbol) are indicated. Left top inset calculated $C_{\mathrm{dl}}$ values as a function of potential

values of $C_{\mathrm{dl}}$ as a function of potential. For $-1,300 \geq E \geq-$ $1,400 \mathrm{mV}$, the values of $C_{\mathrm{dl}}$ are practically potential independent. For this $E$ range, we arbitrarily assume the specific double layer capacitance of $20 \mu \mathrm{F} \mathrm{cm}^{-2}$, a typical value for aqueous electrolytes in the absence of significant specific adsorption [45]. The surface roughness factor obtained for the electrodes studied in this work was in the range of 1933. The amount of the oxidised layer formed can be calculated on the basis of $\mathrm{Co}$ oxidation or $\mathrm{Co}$ (II) reduction charge. We assume that for solid cobalt with hep structure and lattice constant of $0.251 \mathrm{~nm}$ [46], the charge required for complete oxidation of the topmost layer of Co atoms to $\mathrm{Co}$ (II) equals $587 \mu \mathrm{Ccm}^{-2}$. In the further parts of the text, thickness is expressed in monolayers, which indicates the number of topmost layers of Co atoms completely oxidised, i.e. multiplicity of the charge of $587 \mu \mathrm{Ccm}^{-2}$. In the case of $\mathrm{Co}(\mathrm{II})$ layer, the term monolayer means the amount of the oxidised layer containing the amount of $\mathrm{Co}(\mathrm{II})$ formed during complete oxidation of one full atomic layer of Co. When formation of a "chessboard-like" structure of the oxide/ hydroxide is considered [2-4], such a Co(II) monolayer contains at least two atomic layers composed with mixed $\mathrm{Co}^{2+}$ and $\mathrm{O}^{2-}$ or $\mathrm{OH}^{-}$, depending on the structure.

Cyclic voltammetry, EQCM and RRDE measurements

Figure 2 presents the cyclic voltammetry (bottom) and gravimetric (top) curves for an electrodeposited Co electrode 


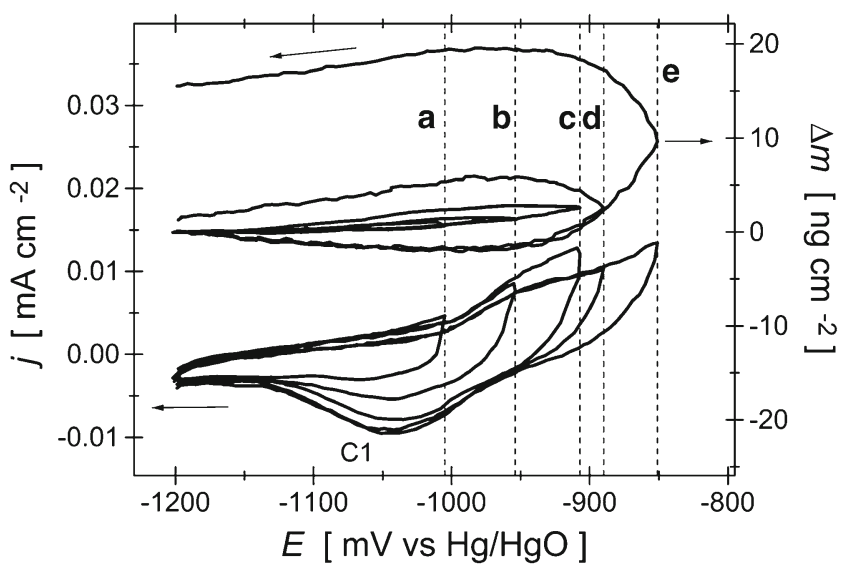

Fig. 2 Cyclic voltammetry (bottom) and gravimetric (top) curves for a Co electrode in $0.1 \mathrm{M} \mathrm{KOH}$ for various anodic potential limits indicated by vertical lines: $a-1,005 \mathrm{mV}, b-954 \mathrm{mV}, c-907 \mathrm{mV}, d-$ $890 \mathrm{mV}, e-810 \mathrm{mV}$. The order of changes of anodic potential limit was as follows: $-1,005,-954,-907,-810$ and $-890 \mathrm{mV} ; 25 \mathrm{mV} \mathrm{s}^{-1}$, room temperature; $C 1$ reduction peak (discussed in the text). The zero mass for gravimetric curves is arbitrarily set at $-1,200 \mathrm{mV}$ for all curves

in $0.1 \mathrm{M} \mathrm{KOH}_{\mathrm{aq}}$ recorded from $-1,200 \mathrm{mV}$ to various anodic potential limits, $E_{\mathrm{a}}$, below $-851 \mathrm{mV}$. Co oxidation currents start at potentials more negative than hydrogen evolution onset (located at ca. $-932 \mathrm{mV}$ ) and rise with the potential increase. These currents are accompanied by an increase in the mass of the electrode, also observed at potentials more negative than HER onset. The cathodic branch of $\mathrm{CV}$ curves exhibits a peak, C1, at ca. - 1,040 mV, which is accompanied by a mass decrease due to reduction of $\mathrm{Co}$ (II) compounds. Peak C1 partially overlaps HER currents. For $E_{\mathrm{a}} \geq-890 \mathrm{mV}$, the mass loss due to surface reduction extends below the apparent end of $\mathrm{C} 1$ peak and the mass loss is also observed during the initial stages of the subsequent anodic cycle (up to ca. $-1,040 \mathrm{mV}$ ). This indicates that $\mathrm{Co}$ (II) layer reduction extends beyond the $\mathrm{C} 1$ peak towards the region of HER.

In [34], it was shown that continuous potential cycling of a Co electrode with anodic potential limit of $-700 \mathrm{mV}$ results in the formation of a hardly reducible layer of $\mathrm{Co}$ (II) compounds. In Fig. 2, the irreversibility of the oxidation process is mirrored by an evolution of CV and EQCM curves. Oxidation currents recorded for $E_{\mathrm{a}}=-890 \mathrm{mV}$ and after previous scans to $E_{\mathrm{a}}=-851 \mathrm{mV}$ are smaller than the currents recorded before $E_{\mathrm{a}}$ was increased to $-851 \mathrm{mV}$ $\left(E_{\mathrm{a}}=-954\right.$ and $-907 \mathrm{mV}$ in Fig. 2). For $E_{\mathrm{a}} \leq-907 \mathrm{mV}$, the gravimetric curve is closed, indicating the insignificance of irreversible oxidation and dissolution. When $E_{\mathrm{a}}$ increases beyond $-907 \mathrm{mV}$, the gravimetric curve becomes open due to the accumulation of a hardly reducible oxidised layer [34]. Further increase in $E_{\mathrm{a}}$ results in continuous evolution of both gravimetric and cyclic voltammetry curves, until a closed gravimetric loop is obtained, similarly to the results obtained in $1 \mathrm{M} \mathrm{KOH} \mathrm{[34]} \mathrm{(results} \mathrm{not} \mathrm{shown).}$
Figure 3 shows the ring currents recorded in RRDE experiments in $0.1 \mathrm{M}$ and $3 \mathrm{M} \mathrm{KOH}$ at 2,500 r.p.m. for two ring potentials $\left(E_{\mathrm{r}}\right):-1,150 \mathrm{mV}$, where $\mathrm{Co}^{2+}$ species are reduced, and $0 \mathrm{mV}$, where $\mathrm{Co}^{2+}$ are oxidised to $\mathrm{Co}^{3+}$. The potentials were not corrected for liquid junction potential between $0.1 \mathrm{M}$ (reference electrode) and $3 \mathrm{M}$ (working electrolyte) $\mathrm{KOH}$. Considering the estimated mobility of $\mathrm{K}^{+}$ions [47], such a potential difference should not exceed $30 \mathrm{mV}$ [48], which is not a significant figure as compared to the potential span of applied $E_{\mathrm{r}}$ values.

When the disk potential $\left(E_{\mathrm{d}}\right)$ is scanned at potentials more positive than $-950 \mathrm{mV}$, we observe an increase in currents recorded in $3 \mathrm{M} \mathrm{KOH}$, cathodic currents for $E_{\mathrm{r}}=-$ $1,150 \mathrm{mV}$ and anodic ones for $E_{\mathrm{r}}=0 \mathrm{mV}$, due to the reduction and oxidation of $\mathrm{Co}(\mathrm{II})$ soluble species, respectively (Fig. 3). These effects are absent in $0.1 \mathrm{M} \mathrm{KOH}$, indicating the insignificance of Co dissolution in the latter medium. Other features observed on ring currents are attributed to processes of hydrogen evolution and oxidation. Hence, a decrease in cathodic current observed for both concentrations when $E_{\mathrm{d}}$ is scanned in the positive direction from 1,250 to $-1,100 \mathrm{mV}$ can be explained as a result of the influence of disk reactions on hydrogen evolution on $\mathrm{Pt}$ ring. The decrease in the anodic ring current observed in $0.1 \mathrm{M} \mathrm{KOH}$ for $E_{\mathrm{r}}=0 \mathrm{mV}$ and for $E_{\mathrm{d}}$ changes from $-1,250$ to $-1,100 \mathrm{mV}$ and which is absent in $3 \mathrm{M} \mathrm{KOH}$ is related to the oxidation of $\mathrm{H}_{2}$ generated during cathodic polarisation. Because the solubility of $\mathrm{H}_{2}$ decreases with the increase in $\mathrm{KOH}$ concentration [49], this effect is less important for a higher concentration of $\mathrm{KOH}$. Based on RRDE results, we can conclude that the solubility of electrodeposited Co electrode polarised up to $-800 \mathrm{mV}$ in $0.1 \mathrm{M} \mathrm{KOH}$ is negligible and that the dissolution process cannot be considered as a step in the formation of the oxidised layer.

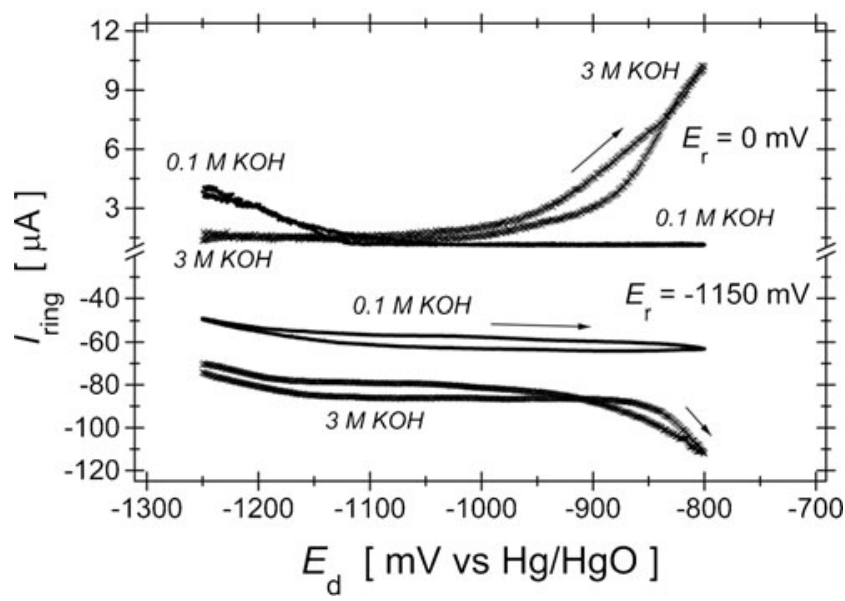

Fig. 3 Ring currents vs. disk potential for RRDE with the ring polarised at $-1,250$ and $0 \mathrm{mV}$ at 0.1 and $3 \mathrm{M} \mathrm{KOH}, 2,500$ r.p.m. Disk potential scanned with $50 \mathrm{mV} \mathrm{s}^{-1}$ from $-1,250$ to $-800 \mathrm{mV}$. The arrows indicate the direction of changes in disk potential 
Constant potential oxidation

The kinetics of Co oxidation at a constant potential value was studied by means of cyclic voltammetry, chronoamperometry, and EQCM. The irreversibility of the surface oxidation process was tested in separate EQCM experiments composed of three steps: (a) prereduction at $-1,200 \mathrm{mV}$, (b) oxidation at a specified potential for a specified time and (c) reduction at $-1,200 \mathrm{mV}$ of the oxidised layer formed in step b. The degree of removal of the oxidised layer during reduction, $\Delta m_{\text {irrev }}$, is defined as the difference between the mass measured at $-1,200 \mathrm{mV}$ in step a, i.e. before the oxidation, and the mass measured in step c, for the reduction time for which the mass becomes approximately constant. This parameter mirrors the reversibility of the oxidation process and is presented in Fig. 4 for various $E_{\mathrm{ox}}$. For $E_{\mathrm{ox}}$ of $-950 \mathrm{mV}$, the oxidised layer is fully reduced, even for $t_{\mathrm{ox}}$ up to $178 \mathrm{~s}$. For higher $E_{\mathrm{ox}}$ values, $\Delta m_{\text {irrev }}$ increases with an increase in $E_{\mathrm{ox}}$ and $t_{\mathrm{ox}}$, indicating the dependence of the oxidation reversibility on $E_{\mathrm{ox}}$ and on the amount of the oxidised layer formed. A similar result is obtained when the reduction potential in steps a and $\mathrm{c}$ is shifted to more negative values down to $-1,350 \mathrm{mV}$. Due to the irreversibility of the oxidation process, the $E_{\mathrm{ox}}$ and $t_{\mathrm{ox}}$ values were limited to $-880 \mathrm{mV}$ and ca. $64 \mathrm{~s}$, respectively.

Figure 5 presents examples of the influence of oxidation time $\left(2 \leq t_{\mathrm{ox}} \leq 45 \mathrm{~s}\right.$.) at $-940 \mathrm{mV}$ on the shape of the cathodic branch of the cyclic voltammetry curves. An increase in $t_{\mathrm{ox}}$ leads to an increase of the charge of peak $\mathrm{C} 1$. An increase in $t_{\mathrm{ox}}$ also leads to an increase in reduction currents at potential more negative than the apparent end of peak $\mathrm{C} 1(E<-1,200 \mathrm{mV}$;

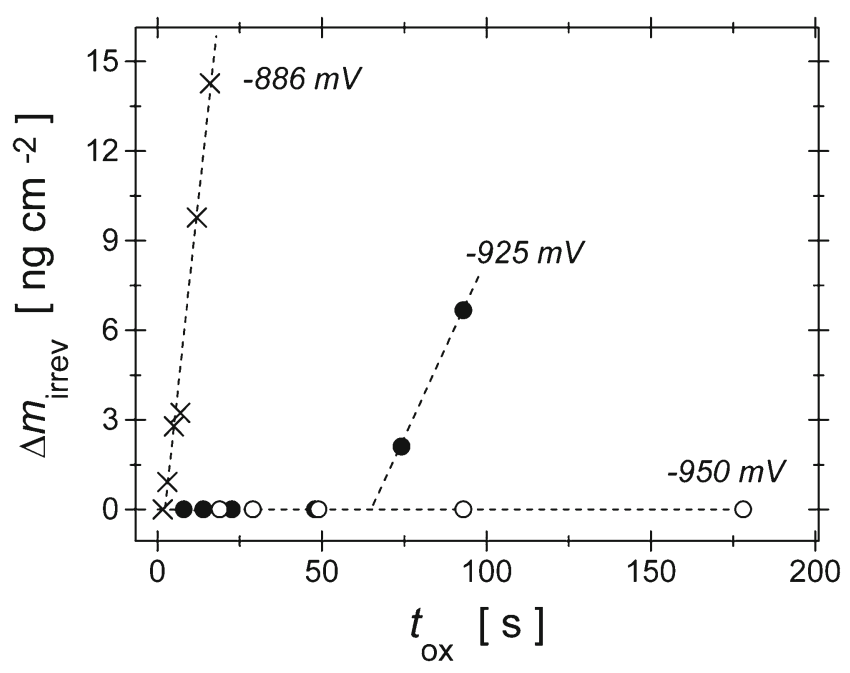

Fig. 4 Oxidation potential and time influence on reversibility of the oxidation process expressed as a mass difference, $\Delta m_{\text {irrev }}$, measured at $-1,200 \mathrm{mV}$ before the oxidation and at $-1,200 \mathrm{mV}$ after reduction of the oxidised layer formed at specified potential for a specified time. The reduction $-1,200 \mathrm{mV}$ was continued until a nearly constant mass was established. Lines are meant as a guide to the eyes
Fig. 5). For higher $t_{\mathrm{ox}}$ values, an inflection at ca. $-1,200 \mathrm{mV}$ is observed, suggesting the formation of an additional reduction peak at $E<-1,200 \mathrm{mV}$. It is likely that $\mathrm{Co}$ (II) reduction may not be completed in the potential range of the $\mathrm{C} 1$ peak. This is in line with EQCM results (Fig. 2) showing that for higher values of $E_{\mathrm{a}}$ the mass loss due to $\mathrm{Co}$ (II) reduction is observed also after the apparent end of peak $\mathrm{C} 1$.

For charge calculation purposes, currents not related to Co(II) reduction, i.e. due to HER and the double layer charging, were eliminated by subtraction of the currents obtained for the shortest $t_{\mathrm{ox}}$ applied, $2 \mathrm{~s}$, from the currents obtained for $t_{\mathrm{ox}}>2 \mathrm{~s}$. The integration covered the potential range from the beginning of peak $\mathrm{C} 1$ to the potential where the currents for $t_{\mathrm{ox}}=2 \mathrm{~s}$ and $t_{\mathrm{ox}}>2 \mathrm{~s}$ overlap. The left inset in Fig. 5 presents semi-logarithmic plots of $t_{\mathrm{ox}}$ influence on such calculated reduction charges, $q_{\text {red }}$, which were obtained for various $E_{\mathrm{ox}}$ values. The plots can be approximated by straight lines, indicating the applicability of the direct logarithmic law of the surface oxidation. Interestingly, good linearity is observed also for $E_{\mathrm{ox}}>-920 \mathrm{mV}$ for which only a fraction of the oxidised layer is reduced (Fig. 4). A linear relation between the charge and $\ln \left(t_{\mathrm{ox}}\right)$ is observed also for $q_{\text {red }}$ obtained by integration in potential range of peak $\mathrm{C} 1$ only (results not shown). For $E_{\mathrm{ox}} \leq-980 \mathrm{mV}$, the values of

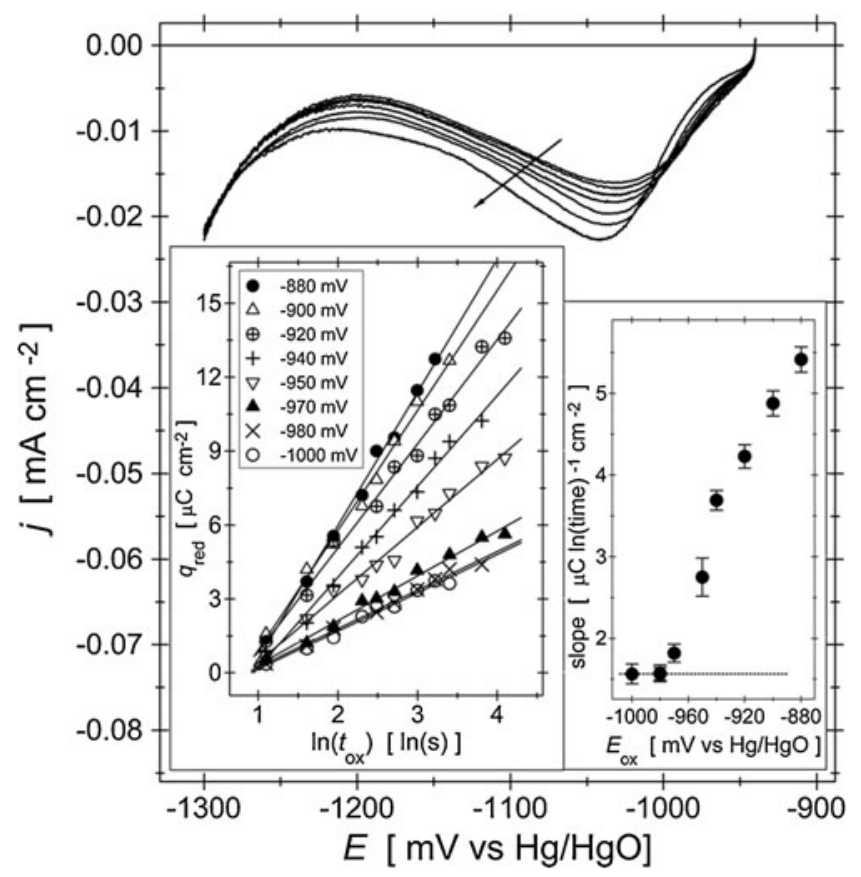

Fig. 5 Top examples of cathodic sections of cyclic voltammetry curves $\left(100 \mathrm{mV} \mathrm{s}^{-1}\right)$ for a Co electrode in $0.1 \mathrm{M} \mathrm{KOH}$ and oxidised at $-940 \mathrm{mV}$ for various oxidation times: $2,3,5,7,12,20$ and $45 \mathrm{~s}$. The arrow indicates changes in the curve resulting from an increase in polarisation time. Left inset influence of the oxidation time, $t_{\mathrm{ox}}$, on the charge of $\mathrm{Co}(\mathrm{II})$ reduction, $q_{\mathrm{red}}$, presented in semi-logarithmic coordinates; oxidation potentials are indicated on the plot. Right inset slope of $q_{\text {red }}$ vs. $\ln \left(t_{\mathrm{ox}}\right)$ plots from the right inset vs. oxidation potential. The horizontal line indicates the region with the slope independent on $E_{\mathrm{ox}}$ 
the slope of these lines are independent on $E_{\mathrm{ox}}$, while for higher oxidation potentials the slope increases with $E_{\mathrm{ox}}$ (right inset in Fig. 5). It should be pointed out that for $E_{\text {ox }}>-920 \mathrm{mV}$, the measured values of the slopes are most likely reduced due to the incomplete reduction of the oxidised layer (Fig. 4), but their increase with $E_{\mathrm{ox}}$ indicates an increase in the oxidation rate with increasing potential also for this $E_{\text {ox }}$ range.

Figure 6 presents mass change, $\Delta m$, vs. oxidation charge, $q_{\mathrm{ox}}$, profiles for constant potential oxidation for $E_{\mathrm{ox}}$ changing from $-1,000$ to $-890 \mathrm{mV}$. Before applying $E_{\mathrm{ox}}$, the electrode was reduced at $-1,250 \mathrm{mV}$. Qualitatively and quantitatively similar results are obtained also for prereduction at $-1,350 \mathrm{mV}$. $q_{\mathrm{ox}}$ was obtained by integration of chronoamperometric curves. For potentials in the HER region $\left(E_{\mathrm{ox}}<-926 \mathrm{mV}\right)$, the charge due to Co oxidation used for construction of the plots was taken only for a short period of $t_{\mathrm{ox}}$ when the oxidation current is much higher than the steady state currents due to HER. Hence, for $E_{\text {ox }}<-926 \mathrm{mV}$, the plots cover only a very narrow range of $q_{\text {ox }}$ values. We note that when extrapolated steady state HER currents are subtracted from Co oxidation currents the obtained values of the slopes of mass vs. charge plots change by no more than ca. $7 \%$ as compared to that presented in Fig. 6. One notes that for $E_{\mathrm{ox}}<-916 \mathrm{mV}$ the plots can be approximated by single straight lines over the whole $t_{\text {ox }}$ period. Such a constant massto-charge ratio indicates that the composition of the oxidation products does not change with the progress in the process. For $E_{\text {ox }} \geq-916 \mathrm{mV}$ and $q_{\text {ox }}>0.05 \mathrm{mC} \mathrm{cm}^{-2}$, a departure from linearity is observed and an additional one linear section is established. This effect takes place in the $E_{\text {ox }}$ range where an increase in the irreversibility of the oxidation process, i.e. $\Delta m_{\text {irrev }} \neq 0$, is observed (see Fig. 4).

The slopes of $\Delta m$ vs. $q_{\text {ox }}$ plots can be recalculated into mass per mole ratios, $M_{\mathrm{a}}$. The latter value represents the mass change per number of the electrons exchanged in the process and is shown in the inset in Fig. 6a as a function of $E_{\text {ox }}$. For $E_{\mathrm{ox}} \geq-916 \mathrm{mV}$, the inset displays $M_{\mathrm{a}}$ values only for the initial linear section of $\Delta m$ vs. $q_{\mathrm{ox}}$ plots for low values of $t_{\mathrm{ox}}$. Comparative experiments performed in $0.1 \mathrm{M} \mathrm{NaOH}_{\mathrm{aq}}$ show no influence of cation identity: $M_{\mathrm{a}}$ obtained for $\mathrm{NaOH}$ were within $\pm 6 \%$ of the values for $0.1 \mathrm{M} \mathrm{KOH}$. The maximum value of $M_{\mathrm{a}}$ of ca. $12.5 \mathrm{gmol}^{-1}$ is obtained for $E_{\mathrm{ox}}=-988 \mathrm{mV}$. For the lowest $E_{\text {ox }}$ applied $(-1,000 \mathrm{mV})$, the $M_{\mathrm{a}}$ value is ca. $11.3 \mathrm{~g} \mathrm{~mol}^{-1}$. An increase in potential above $-988 \mathrm{mV}$ leads to a decrease in $M_{\mathrm{a}}$, which eventually reaches the value in the range of $6.5-5.5 \mathrm{~g} \mathrm{~mol}^{-1}$ for $E_{\mathrm{ox}}>-922 \mathrm{mV}$.

The presented $M_{\mathrm{a}}$ values point to changes in composition of the Co oxidation products: the oxidised layer formed at $E_{\mathrm{ox}}<-970 \mathrm{mV}$ contains significant amounts of $\mathrm{Co}(\mathrm{OH})_{2}$ (theoretical $M_{\mathrm{a}}=17 \mathrm{~g} \mathrm{~mol}^{-1}$ ), while at more positive potentials the presence of $\mathrm{CoO}$ is detected (theoretical $M_{\mathrm{a}}=8 \mathrm{~g}$ $\mathrm{mol}^{-1}$ ). These conclusions are in line with XPS results which are discussed further in the text. The obtained order
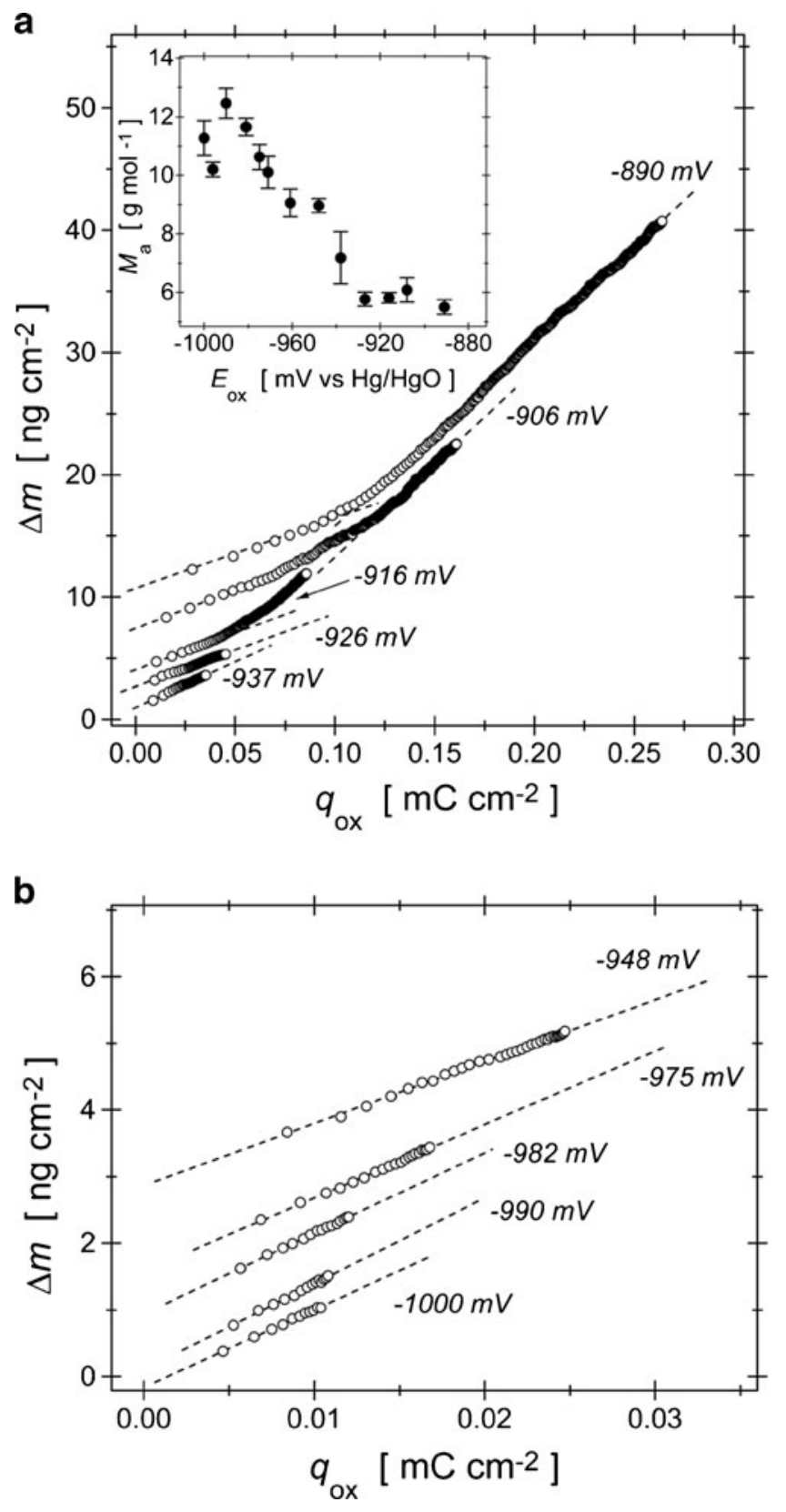

Fig. 6 Mass change, $\Delta m$, vs. oxidation charge, $q_{\mathrm{ox}}$, profiles recorded during oxidation of a Co electrode in $0.1 \mathrm{M} \mathrm{KOH}$ at various $E_{\mathrm{ox}}$ : a from -937 to $-890 \mathrm{mV}$, b from $-1,000$ to $-948 \mathrm{mV}$. For clarity, the curves for various values of $E_{\mathrm{ox}}$ are arbitrarily shifted in the mass scale. Application of the oxidation potential was preceded by a reduction of the electrode at $-1,250 \mathrm{mV}$. Inset in $\mathbf{a}$, influence of the oxidation potential on molar mass of Co oxidation products, $M_{\mathrm{a}}$, obtained from the slopes of $\Delta m$ vs. $q_{\text {ox }}$ plots

of formation of $\mathrm{Co}$ (II) compounds corresponds well to the order of standard potentials, $E^{0}$, of $\mathrm{Co}(\mathrm{OH})_{2}$ and $\mathrm{CoO}[22$, $50,51]$, with $E^{0}$ of the latter being more positive than for $\mathrm{Co}$ $(\mathrm{OH})_{2}$. The fact that the obtained $M_{\mathrm{a}}$ values are smaller than the ones theoretically predicted is attributed to participation of adsorbed $\mathrm{H}_{2} \mathrm{O} / \mathrm{OH}^{-}$in the oxidation process. For $E_{\mathrm{ox}}<-$ $970 \mathrm{mV}$, the lowering of $M_{\mathrm{a}}$ values due to a contribution 
from the formation of some amounts of $\mathrm{CoO}$ should also be considered. A comparison of Figs. 4 and 6 indicates the existence of a relation between the oxidised layer composition and the reversibility of the oxidation: $\Delta m_{\text {irrev }} \neq 0$ is observed for $E_{\text {ox }}$ range where $M_{\mathrm{a}}$ falls below $8 \mathrm{~g} \mathrm{~mol}^{-1}$ (Fig. 4).

Intermediate values of $M_{\mathrm{a}}$ observed in the inset in Fig. 6a for $-975 \leq E_{\mathrm{ox}} \leq-930 \mathrm{mV}$ point to generation of a layer composed of both $\mathrm{CoO}$ and $\mathrm{Co}(\mathrm{OH})_{2}$. The formation of a layered structure composed of the oxide and hydroxide was proposed for Co oxidation in alkaline electrolytes on the basis of ellipsometric measurements [52]. This was observed, however, for the multilayered oxidised layers with thickness in the range of a few nanometers. The thickness of the oxidised layers studied in this work can be estimated on the basis of the oxidation charges. For $E_{\mathrm{ox}}=-890 \mathrm{mV}$ and $t_{\mathrm{ox}}=64 \mathrm{~s}$, we obtain the surface coverage of ca. $45 \%$. This value suggests that for $-975 \leq E_{\mathrm{ox}} \leq-930 \mathrm{mV}$, the $\mathrm{CoO}$ and $\mathrm{Co}(\mathrm{OH})_{2}$ should form separate $2 \mathrm{D}$ areas rather than a multilayered $3 \mathrm{D}$ structure.

The second linear section of $\Delta m$ vs. $q_{\text {ox }}$ plots observed for $E_{\mathrm{ox}}-916 \mathrm{mV}$ and for longer $t_{\mathrm{ox}}$ values has a slope of ca. $15 \mathrm{~g} \mathrm{~mol}^{-1}$. We attribute this value to the formation of hydrated $\mathrm{CoO}$ rather than $\mathrm{Co}(\mathrm{OH})_{2}$, the effect being confirmed by XPS results which are presented in the later part of the text, showing the formation of significant amounts of $\mathrm{CoO}$ in this $E_{\mathrm{ox}}$ range. As it will be shown later, $\mathrm{Co}(\mathrm{II})$ layer compositions determined from EQCM measurements correspond to XPS results (Fig. 9), indicating that EQCM response can be interpreted in terms of pure mass changes.

When the molar mass of the oxidation products does not change during the process, the $\Delta m$ vs. $t_{\text {ox }}$ profiles are indicators of the kinetics of the reaction with similar mathematics applied as in the case of charge vs. time relation. Figure 7 shows $\Delta m$ vs. $\ln \left(t_{\text {ox }}\right)$ plots for Co oxidation at $-1,000 \leq E_{\text {ox }} \leq$ $-890 \mathrm{mV}$ and for $t_{\mathrm{ox}}$ of up to 8.6-64 s. The respective $q_{\mathrm{ox}} \mathrm{vs}$. $\ln \left(t_{\mathrm{ox}}\right)$ plots are presented in Fig. 8; for $E_{\mathrm{ox}}<-916 \mathrm{mV}$, the charge used for construction of the plots is the one recorded for the initial $t_{\mathrm{ox}}$ period when the oxidation current is much higher than the steady state HER currents. Both figures were constructed on the basis of the data presented in Fig. 6 .

The inset in Fig. 8a shows a magnification of initial sections of chronoamperometric curves recorded with RRDE at two oxidation potentials and for two rotation rates. The shape of these transients is typical for all $E_{\text {ox }}$ values applied and also for stationary constant potential oxidation. One would note the absence of a nucleation peak [53, 54], indicating that the nucleation and growth models, both 2D and 3D with bulk and surface diffusion, are not applicable. Rotation rate-independent current transients indicate that the rate of the oxidation process is not determined by transport in the electrolyte.

Figures 7 and 8 show that:

1. For $E_{\mathrm{ox}}<-948 \mathrm{mV}$, the $\Delta m$ vs. $\ln \left(t_{\mathrm{ox}}\right)$ plots reveal a good linearity for the entire $t_{\mathrm{ox}}$ range (Fig. 7). For higher $E_{\mathrm{ox}}$

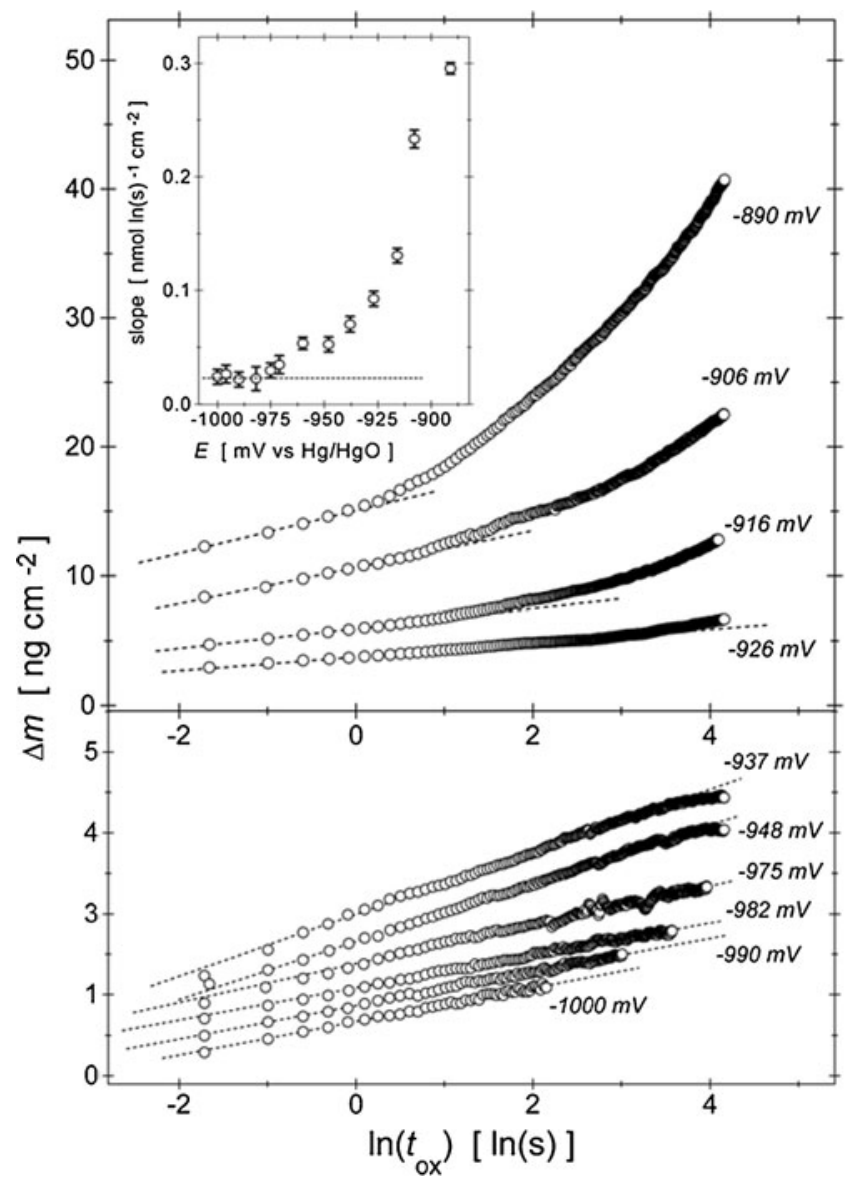

Fig. 7 Semi-logarithmic plots of mass change, $\Delta m$, vs. oxidation time for oxidation of a Co electrode in $0.1 \mathrm{M} \mathrm{KOH}$ for various oxidation potentials indicated on the plot (data from Fig. 6). For clarity, the curves for various values of $E_{\mathrm{ox}}$ are arbitrarily shifted in the vertical scale. The inset shows slopes of $\Delta m$ vs. $\ln \left(t_{\mathrm{ox}}\right)$ plots as a function $E_{\mathrm{ox}}$. The horizontal line in the inset indicates the region where the slope is independent on $E_{\mathrm{ox}}$. The error bars for the inset are comparable to the size of the points

values, only the initial section of the plots is linear; for longer $t_{\mathrm{ox}}$ values, a departure from linearity is observed: downwards for $E_{\mathrm{ox}}=-937$ and $-948 \mathrm{mV}$ and, more pronounced, upwards for $E_{\mathrm{ox}} \geq-926 \mathrm{mV}$.

2. For $E_{\mathrm{ox}}<-916 \mathrm{mV}$, the $q_{\mathrm{ox}} \mathrm{vs} . \ln \left(t_{\mathrm{ox}}\right)$ plots are linear with a single slope over the whole $t_{\mathrm{ox}}$ range presented (Fig. 8). It should be noted that the oxidation currents recorded in this $E_{\mathrm{OX}}$ range can be influenced by contribution from parallel currents due to HER. However, the good linearity of $q_{\mathrm{ox}} \mathrm{vs} . \ln \left(t_{\mathrm{ox}}\right)$ plots correspond well to the linear shapes of $\Delta m$ vs. $\ln \left(t_{\text {ox }}\right)$ (Fig. 7) and $q_{\text {red }}$ vs. $\ln \left(t_{\text {ox }}\right)$ (Fig. 5) plots observed in the same range of $E_{\mathrm{ox}}$. This indicates that the plots presented in Fig. 8 can be treated as reliable indicators of Co oxidation mechanism even at potentials of HER. For $E_{\mathrm{ox}} \geq-916 \mathrm{mV}$, two linear sections are observed in Fig. 8. The length of the first linear section (low $t_{\mathrm{ox}}$ values) decreases with an increase in $E_{\mathrm{ox}}$. The second linear section, observed for $E_{\mathrm{ox}} \geq-916 \mathrm{mV}$, has a higher slope, starts at 

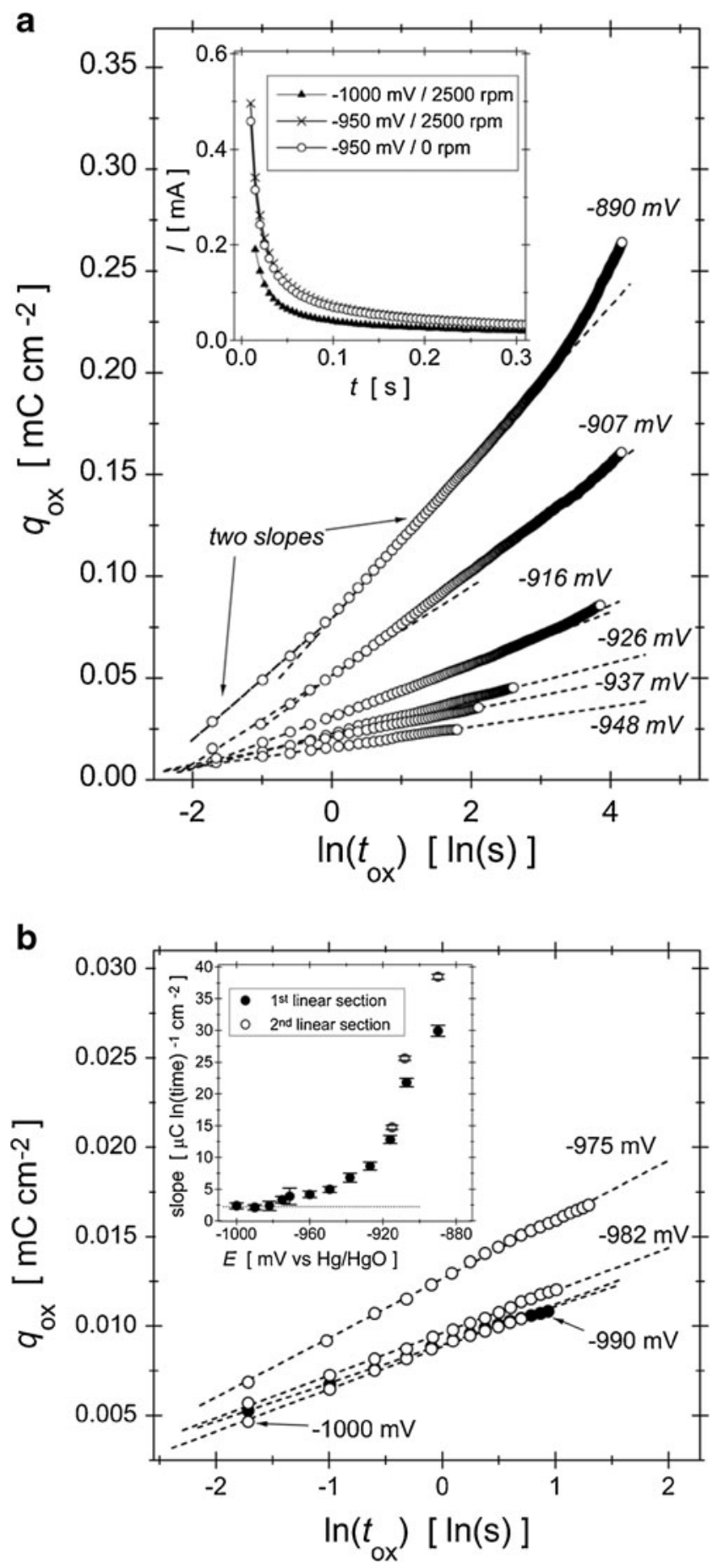

Fig. 8 Semi-logarithmic plots of oxidation charge, $q_{\text {ox }}$, vs. oxidation time recorded during constant potential oxidation in $0.1 \mathrm{M} \mathrm{KOH}$ at various $E_{\mathrm{ox}}$ (data from Fig. 6): a from -948 to $-890 \mathrm{mV}$, b from $-1,000$ to $-975 \mathrm{mV}$. The arrows in a indicate the two slopes of the linear section of the plots discussed in the text. Inset in a, initial sections of chronoamperometric curves for oxidation of a Co electrode in RRDE experiments for two oxidation potentials: $-1,000 \mathrm{mV}(2,500$ r.p.m.) and $-950 \mathrm{mV}$ (disk currents, 2,500 and 0 r.p.m.). Inset in $\mathbf{b}$, slopes of $q_{\mathrm{ox}} \mathrm{vs.} \ln \left(t_{\mathrm{ox}}\right)$ plots as a function $E_{\mathrm{ox}}$. The horizontal line in the inset indicates the region where the slope is independent on $E_{\mathrm{ox}}$. The open circles represent the slopes of the second linear sections observed for $E_{\mathrm{ox}}>-920 \mathrm{mV}$ and discussed in the text. The error bars for the inset are comparable to the size of the points longer oxidation times and extends to $\ln \left(t_{\mathrm{ox}}\right)$ of ca. 3.2, where further changes in the shape of the plots are seen.

3. The slopes of linear sections of both $\Delta m$ vs. $\ln \left(t_{\mathrm{ox}}\right)$ and $q_{\text {ox }}$ vs. $\ln \left(t_{\text {ox }}\right)$ plots are presented in insets in Figs. 7 and 8 b, respectively. For $\Delta m$ vs. $\ln \left(t_{\mathrm{ox}}\right)$ plots, the slopes were divided by $M_{\mathrm{a}} / F$, where $F$ is the Faraday constant. Such obtained values are independent on the composition of the oxidation products and are direct indicators of the kinetics of the process for $t_{\mathrm{ox}}$ range for which $M_{\mathrm{a}}$ is constant (Fig. 6). One notes that for $E_{\mathrm{ox}} \leq-980 \mathrm{mV}$, the slopes are independent on $E_{\mathrm{ox}}$ (insets in Figs. 7 and 8b, respectively). For $E_{\mathrm{ox}}>-980 \mathrm{mV}$, the slopes of both plots increase with an increase in $E_{\mathrm{ox}}$. A similar shape of slope vs. $E_{\mathrm{ox}}$ relation was obtained also from cyclic voltammetry measurements (Fig. 5).

4. The values of the slopes obtained from CV (Fig. 5) are smaller compared to CA (Fig. 8b): from 1.5 to 1.9 times for $E_{\text {ox }}$ below $-920 \mathrm{mV}$ and up to 5.8 times for $-880 \mathrm{mV}$. These differences mirror the complications with separation of overlapping currents of HER and $\mathrm{Co}$ (II) reduction in CV experiments. Further on, the irreversibility of $\mathrm{Co}$ (II) formation for $E_{\text {ox }}>-920 \mathrm{mV}$ leads to an incomplete reduction of $\mathrm{Co}$ (II) layer during single, negative $\mathrm{CV}$ scan and increases the differences between values of the slopes obtained for $\mathrm{CV}$ and CA.

5. Changes in the shape/slope of $\Delta m$ vs. $\ln \left(t_{\mathrm{ox}}\right)$ and $q_{\mathrm{ox}}$ vs. $\ln \left(t_{\mathrm{ox}}\right)$ plots (Figs. 7 and 8 ) can be linked to the evolution of $\Delta m$ vs. $q_{\text {ox }}$ curves (Fig. 6). $\Delta m$ vs. $q_{\text {ox }}$ plots exhibit departures from linearity for $E_{\mathrm{ox}} \geq-926 \mathrm{mV}$ and this corresponds to (a) a departure from linearity of $\Delta m$ vs. $\ln \left(t_{\mathrm{ox}}\right)$ plots $\left(E_{\mathrm{ox}} \geq-926 \mathrm{mV}\right.$ in Fig. 7) and (b) the appearance of the second linear section in $q_{\mathrm{ox}}$ vs. $\ln \left(t_{\mathrm{ox}}\right)$ curves $\left(E_{\mathrm{ox}} \geq-\right.$ $916 \mathrm{mV}$ in Fig. 8a).

X-ray photoelectron spectroscopy

Very thin oxidised layers with estimated thickness not greater than $50 \%$ of the monolayer are hard to measure using ex situ techniques. Complications are related to the disputable stability of such thin layers when examined under ex situ conditions and to the accuracy of separation of a small Co(II) photopeak from a prevailing $\mathrm{Co}(0)$ signal. In order to obtain more reliable results of ex situ measurements, the XPS technique was applied for the analysis of the oxidised layers with thickness greater than those presented in Figs. 6, 8 and 9.

Figure 9 presents the XPS spectra recorded for Co samples oxidised for $300 \mathrm{~s}$ at two potentials ( -980 (Fig. 9b) and $-890 \mathrm{mV}$ (Fig. 9c)) and for a Co deposit subjected to etching with $\mathrm{Ar}^{+}$gun (Fig. 9a). A detailed discussion of the structure of $\mathrm{Co}$ (II) spectra can be found elsewhere [55-58]; here we focus mainly on the binding energies of main, nondeconvoluted Co $2 \mathrm{p} 3 / 2$ peak and its satellites located at higher energies. For Ar-sputtered $\mathrm{Co}(0)$ (Fig. 9a), we observe the main $2 \mathrm{p} 3 / 2$ peak at $778.2 \mathrm{eV}$ and a $2 \mathrm{p} 1 / 2$ peak at $793.2 \mathrm{eV}$, in agreement with the literature $[55,59]$. The 


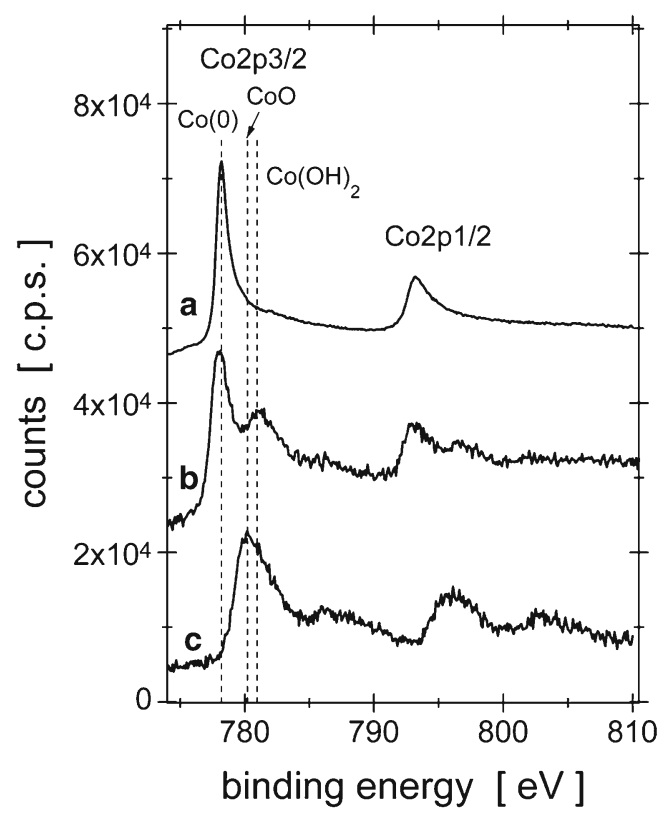

Fig. 9 XPS spectra recorded for Co electrodes studied (a) after cleaning by $\mathrm{Ar}^{+}$sputtering and after oxidation $(b)$ at $-980 \mathrm{mV}$ for $300 \mathrm{~s}$ and (c) at $-890 \mathrm{mV}$ for $300 \mathrm{~s}$. The vertical lines show the locations of $2 \mathrm{p} 3 / 2$ peaks for $\mathrm{Co}(0)(778.2 \mathrm{eV}), \mathrm{Co}(\mathrm{II})$ in $\mathrm{CoO}(780.2 \mathrm{eV})$ and $\mathrm{Co}(\mathrm{II})$ in $\mathrm{Co}$ $(\mathrm{OH})_{2}(780.9 \mathrm{eV})$

satellite of $2 \mathrm{p} 3 / 2$ peak is usually poorly developed (ca. $781 \mathrm{eV}$ [55]) and cannot be distinguished from spectrum a without deconvolution. Figure 9a indicates that the obtained electrodeposits are composed of the metallic Co. The spectrum for $-980 \mathrm{mV}$ (Fig. 9b) shows a decrease in $\mathrm{Co}(0)$ peaks upon oxidation time and reveals new developing peaks: broad $2 \mathrm{p} 3 /$ 2 peak at ca. $780.9 \mathrm{eV}$ and $2 \mathrm{p} 1 / 2$ at $796.5 \mathrm{eV}$. The spectrum recorded for the sample oxidised at $-890 \mathrm{mV}$ shows $\mathrm{Co}(\mathrm{II})$ peaks at energies lower than for $-980 \mathrm{mV}$ : a main $2 \mathrm{p} 3 / 2$ peak at $780.2 \mathrm{eV}$ with a satellite at $785.7 \mathrm{eV}$ and a $2 \mathrm{p} 1 / 2$ peak at $796.2 \mathrm{eV}$ with a satellite at $803 \mathrm{eV}$.

Literature data $[55,58,59]$ indicate that for $\mathrm{CoO}$ the $2 \mathrm{p} 3 /$ 2 and $2 \mathrm{p} 1 / 2$ peaks are located at binding energies lower than for $\mathrm{Co}(\mathrm{OH})_{2}$. The spectra shown in Fig. 9 indicate the existence of $\mathrm{Co}(\mathrm{OH})_{2}$ at $-980 \mathrm{mV}$ and $\mathrm{CoO}$ at $-890 \mathrm{mV}$, in agreement with EQCM data (Fig. 6). The fact that the XPS results are in line with EQCM data indicates that the frequency response of the microbalance is determined by pure mass changes. We note that for $E_{\mathrm{ox}}=-890 \mathrm{mV}$ (Fig. 9 (c)), the ratio between areas of $2 \mathrm{p} 1 / 2$ peak and its satellite is ca. 2, indicating the absence of $\mathrm{Co}$ (III) forms for which the satellite should be much smaller as compared to the main $2 \mathrm{p} 1 / 2$ peak or even not observed $[55,60]$.

Discussion of the oxidation model

Three independent techniques, CV, CA and EQCM, reveal that early stages of Co oxidation in an alkaline electrolyte, i.e. up to ca. $50 \%$ of the single monolayer, follow a direct logarithmic law (Figs. 5, 7 and 8). These three techniques also reveal that for $E_{\mathrm{ox}}>-980 \mathrm{mV}$, the slope of semilogarithmic plots increases with $E_{\mathrm{ox}}$, while for lower oxidation potential values the slope is $E_{\mathrm{ox}}$ independent (insets in Figs. 5, 7 and $8 b$ ).

For electrochemical oxidation, the direct logarithmic law of oxide/hydroxide growth was discussed in $[4,6,8]$ and the respective models have been derived. In [4], it was assumed that oxidation leads to the formation of a chessboard-like structure with uniformly mixed metal and oxygen $/ \mathrm{OH}^{-}$ions. The rate-determining step (r.d.s.) in this model is a rotation of metal-oxygen dipoles in the electric field established at the interface ("place exchange" model). The main equation used in this model has the following form (one electron transfer $[1,4])$ Eq. 3 :

$q=a \ln \left(t_{o x}\right)+b$

with Eq. 3a:

$a=\frac{d_{M L} A_{r} R T F \varepsilon_{0}}{2 N_{A}^{2} \beta \mu^{2}}$

where $\beta$ is the symmetry factor (assumed to be 0.5 ), $\mu$ is the dipole moment of rotating species, $d_{\mathrm{ML}}$ is the thickness of the monolayer of rotating species and the other parameters have their usual meaning. The intercept $b$ is a function of $A_{\mathrm{r}}, \mu, \beta$ and $\varepsilon_{0}$ and depends also on a rate constant, $k$, potential drop across the layer of the dipoles, $\Delta E$, and on the surface potential due to the presence of water molecules in the double layer, $\Delta \varphi$. The exact mathematical form of the intercept is presented in $[1,4]$, and in this paper we do not discuss this parameter in detail since it contains too many unknown parameters $(k, \Delta E$, $\Delta \varphi$ ). The dependence of the intercept $b$ on potential is complex [1, 4], while the slope of Eq. 3 is potential independent. This model was applied mainly for the formation of oxidised layers with thickness not greater than that of the monolayer [1-3], which corresponds to the range of thickness of $\mathrm{Co}$ (II) layers studied in this work.

The model considered in [6] assumes the oxidation process following nucleation and growth pathway. The following equation was derived [6] Eq. 4:

$q=a^{\prime} \eta \log \left(t_{o x}\right)-\frac{a^{\prime} \eta}{6} \log (q)+b^{\prime}$

with Eq. 4a:

$a^{\prime}=\frac{3 z e_{0}}{\Pi v f k_{B} T \sigma^{2}}$

where $v$ is the volume of the molecule, $z$ is the number of the electrons exchanged, $e_{0}$ is the elementary charge, $\eta$ is the 
overpotential, $\sigma$ is the surface free energy, $f$ is a factor used for conversion between charge and thickness units and the other terms have their usual meaning. Similarly to Eq. 3, the intercept $b^{\prime}$ in Eq. 4 is a function of $a^{\prime}$ and depends also on $\eta$ and on the electrochemical rate constant [6]. When $a^{\prime} \eta$ is not greater than unity, the term containing $\log (q)$ can be neglected in Eq. 4 and the slope of the semi-logarithmic relation between the charge and $\log \left(t_{\mathrm{ox}}\right)$ is a linear function of the potential.

The point defect model $[8,61,62]$ also predicts a linear relation between the amount of the oxidised layer formed and $\ln \left(t_{\mathrm{ox}}\right)$ with the slope inversely dependent on the electric field, i.e. applied potential. This model, however, is predicted for the thickness above one monolayer [8], beyond the thickness range studied in the present work.

The existence of a potential-independent slope of semilogarithmic plots, in agreement with the "place exchange" model Eq. 3, is observed in Figs. 5, 7 and $8 \mathrm{~b}$ for $E_{\text {ox }} \leq-$ $980 \mathrm{mV}$. This $E_{\text {ox }}$ range corresponds well to potentials where $\mathrm{Co}(\mathrm{OH})_{2}$ is the prevailing product of the oxidation process (Fig. 6a). Application of the "direct logarithmic law" model for the formation of $\mathrm{Co}(\mathrm{OH})_{2}$ requires some assumptions about the details of the process. First, we assume that both electrons to be exchanged during Co atom oxidation are transferred in separate steps [63-65]. The first step in the oxidation process would then be the formation of $\mathrm{Co}(\mathrm{OH})$ structures at the electrode surface. Further on, it is likely that the rotating species is $\mathrm{Co}(\mathrm{OH})$ rather than $\mathrm{Co}$ $(\mathrm{OH})_{2}$ since the former should possess a relatively high dipole moment. Hence, the order of the steps in the process of Co oxidation at $E_{\mathrm{ox}} \leq-980 \mathrm{mV}$ is expected to be the same as for Ni oxidation as discussed in [7]: (1) fast transfer of the first electron to form $\mathrm{Co}(\mathrm{OH})$, (2) slow rotation of $\mathrm{Co}(\mathrm{OH})$ dipole (rate-determining step) and (3) fast transfer of the second electron and formation of Co(II) hydroxide molecule.

At $E_{\text {ox }}>-980 \mathrm{mV}$, where the presence of $\mathrm{CoO}$ is detected (Figs. 6 and 9), the values of the slopes in Figs. 5, 7 and 8b are higher than for $\mathrm{Co}(\mathrm{OH})_{2}$ region and, in contrast to Eq. 3, the slopes strongly depend on $E_{\mathrm{ox}}$. As was discussed earlier (Fig. 6a), for $-975 \leq E_{\text {ox }} \leq-930 \mathrm{mV}$, the electrode surface contains oxidised areas composed of $\mathrm{CoO}$ and $\mathrm{Co}(\mathrm{OH})_{2}$. We assume that the formation of $\mathrm{CoO}$ and $\mathrm{Co}(\mathrm{OH})_{2}$ proceeds independently, both according to the direct logarithmic law. Increasing the contribution from $\mathrm{CoO}$ would result in continuous changes of the slopes with $E_{\mathrm{ox}}$. However, due to a contribution from $\mathrm{OH}$ bond, the $\mathrm{Co}(\mathrm{OH})$ dipole moment should be smaller than for $\mathrm{CoO}$ and slope a in Eq. 3a in the potential region of $\mathrm{CoO}$ formation should be smaller than for $\mathrm{Co}(\mathrm{OH})_{2}$, opposite to what is seen Figs. 5, 7 and 8b. Further on, the slope of the first linear section from Fig. $8 \mathrm{a}$ increases also at potentials where the oxidised layer composition is unchanged (constant $M_{\mathrm{a}}$ in Fig. 6a). Thus, it is likely that the rate of oxidation not only depends on the composition but is also strongly influenced by the oxidation potential itself. The nucleation model (Eqs. 4 and 4 a) also seems to be not applicable. The current-time profiles recorded for Co oxidation (inset in Fig. 8a) do not exhibit a nucleation peak, usually observed for nucleation and growth mechanism. Although a model of 2D layer growth controlled by instantaneous nucleation and according to Avrami theorem predicts a current decay without the peak [66], a linear relationship between the charge and $\ln \left(t_{\mathrm{ox}}\right)$ is not obtained [66]. Further on, Eq. 4 predicts a linear relation between the slope of $q$ vs. $\ln \left(t_{\mathrm{ox}}\right)$ plots and potential, while Figs. 5, 7 and $8 \mathrm{~b}$ indicate that the relation can be roughly approximated by a straight line only for CA.

A potential influence on the slope of the direct logarithmic law describing metal oxidation (Eqs. 3 and 3a) was observed for oxidation of $\mathrm{Au}$ [4] and Pt [5] in acidic solutions and for polycrystalline $\mathrm{Ni}$ in $0.5 \mathrm{M} \mathrm{KOH} \mathrm{[7].} \mathrm{In} \mathrm{the}$ case of $\mathrm{Au}$, the effect was explained as a result of anion adsorption, while for the nickel it was attributed to various oxidation rates of different crystallographic planes exposed to the electrolyte. In all of these cases, however, the potential influence on the slopes was smaller than those presented in Figs. 5, 7 and 8 b (ca. $270 \%$ for $200 \mathrm{mV}$ range for $\mathrm{Au}$ [4], ca. $100 \%$ for $200 \mathrm{mV}$ range for Pt [5] and below $10 \%$ for $200 \mathrm{mV}$ range for $\mathrm{Ni}$ (room temperature [7])) as compared to $300-900 \%$ for $100 \mathrm{mV}$ range measured in this work for $\mathrm{CV}$ and CA, respectively. Such huge changes cannot be attributed to the influence of crystallographic orientation on the oxidation process, especially when one considers that the potential influence on the slope of the direct logarithmic law was observed also for Pt single crystals [5]. Intuitively, the extent of the potential impact of the discussed slopes cannot be attributed to the contribution from $E$-dependent ion adsorption. When adsorption of cations is excluded (discussion of Fig. 6), the only ion which can adsorb on the electrode surface is $\mathrm{OH}^{-}$. These ions do not block the surface for surface oxidation and most likely participate directly in the surface oxidation process. They may affect the surface oxidation process by changing the electric field at the interface, but the extent of this effect seems to be rather smaller than the $E_{\mathrm{ox}}$ influence on the slopes of the plots in Figs. 5, 7 and 8b.

The discussed potential influence on the slopes of semilogarithmic plots cannot be also attributed to the irreversibility of the oxidation process: the effect of the slope increase is observed already for $E_{\mathrm{ox}}$ and $t_{\mathrm{ox}}$ range where the oxidation process can be considered as reversible (Fig. 4).

The preceding discussion shows that oxidation of Co in $0.1 \mathrm{M} \mathrm{KOH}$ at $E_{\text {ox }}>-980 \mathrm{mV}$ cannot be successfully described by already known oxidation models [4, 6]; a new model of surface oxidation process should be considered. 
The presented results allow us to draw some conclusions which may be helpful in the development of a new surface oxidation model. The most striking difference between processes taking place above and below $-975 \mathrm{mV}$ is related to the form of oxygen containing species present in the oxidised layer. For $E_{\mathrm{ox}}<-975 \mathrm{mV}$, this is mainly $\mathrm{OH}^{-}$, while for $E_{\mathrm{ox}}>-975 \mathrm{mV}$ the oxidised layer contains significant amounts of $\mathrm{O}^{2-}$. While $\mathrm{OH}^{-}$ions are present in the electrolyte or can be easily formed during $\mathrm{H}_{2} \mathrm{O}$ dissociation, $\mathrm{O}^{2-}$ must be generated in a separate reaction of $\mathrm{H}_{2} \mathrm{O} / \mathrm{OH}^{-}$decomposition and such a step must be included in the overall oxidation mechanism for $E_{\mathrm{ox}}>-980 \mathrm{mV}$. Further on, the direct logarithmic law requires the driving force of the process to decrease with the progress in the process (or, alternatively, energy barrier must increase with the progress). Next, a smooth transition between mechanisms taking place below and above $-980 \mathrm{mV}$ is expected when $E_{\mathrm{ox}}$ increases. Finally, it is likely that the r.d.s. is not the electron transfer, which is assumed to be very fast, but other process, e.g. $\mathrm{H}_{2} \mathrm{O}$ decomposition to form $\mathrm{O}^{2-}$ or phase oxide formation.

Based on the cited suppositions, we can briefly discuss the possible steps contributing to Co oxidation process at $E_{\text {ox }}>-980 \mathrm{mV}$. When $E_{\text {ox }}$ increases, the rate of transfer of both electrons also increases, and for high-enough values of $E_{\mathrm{ox}}$ the transfer of the second electron may proceed before the slow "place exchange" step [4]. This leads to the formation of $\mathrm{Co}^{2+}$ species stabilised at the surface by interaction with $\mathrm{OH}^{-}$or $\mathrm{H}_{2} \mathrm{O}$. In the subsequent steps, $\mathrm{OH}^{-} / \mathrm{H}_{2} \mathrm{O}$ decompose to generate $\mathrm{O}^{2-}$, and a phase oxide is formed. The latter steps are expected to be the r.d.s. (fast transfers of both electrons are treated as in a pseudo-equilibrium state). Charged species take part in $\mathrm{H}_{2} \mathrm{O}$ decomposition to $\mathrm{O}^{2-}$, and the rate of this step may depend on $E_{\text {ox }}$. The electric field at the interface changes with oxidation progress due to the formation of oxide, and this may increase the energy barrier when $t_{\mathrm{ox}}$ increases, leading to the shape of time profiles shown in Figs. 5, 7 and 8. The said scenario resembles an EEC mechanism but with the rate of the chemical step (C) affected by the electric field at the interface.

\section{Conclusions}

The oxidation of electrodeposited cobalt electrodes has been studied in $0.1 \mathrm{M} \mathrm{KOH}_{\mathrm{aq}}$ solution in the potential range $-1,000$ to $-880 \mathrm{mV}$ vs. $\mathrm{Hg} \mid \mathrm{HgO}$ where $\mathrm{Co}$ (II) compounds are formed. Four electrochemical techniques were applied to study the mechanism of the process: cyclic voltammetry, chronoamperometry, electrochemical quartz crystal microbalance and rotating ring disk electrode. We found that:

- The solubility of electrodeposited Co in $0.1 \mathrm{M} \mathrm{KOH}$ at potentials more negative than $-800 \mathrm{mV}$ vs. $\mathrm{Hg} \mid \mathrm{HgO}$ is negligible and does not constitute a step in the process of formation of the oxidised layer.

- The reversibility of the oxidation process decreases when the oxidation potential and the amount of the oxidised layer formed increase.

- EQCM and X-ray photoelectron spectroscopy experiments reveal the formation of significant amounts of $\mathrm{Co}$ $(\mathrm{OH})_{2}$ at oxidation potentials below $-975 \mathrm{mV}$ vs. $\mathrm{Hg}$ $\mathrm{HgO}$, while at potentials positive to this value $\mathrm{CoO}$ existence is detected.

- Three techniques (CV, CA and EQCM) reveal that below $-880 \mathrm{mV}$ vs. $\mathrm{Hg} \mid \mathrm{HgO}$, the oxidation of $\mathrm{Co}$ electrode follows a direct logarithmic law.

- An analysis of direct logarithmic law shows that at potentials not higher than $-980 \mathrm{mV}$ vs. $\mathrm{Hg} \mid \mathrm{HgO}$, the "electric field-assisted place exchange" model can correctly describe the oxidation process. At more positive potentials, this model does not correctly describe the influence of oxidation potential on the process in question. Further elucidation of the mechanism linked to the direct logarithmic law of growth of oxidised layers is required.

Acknowledgments This work was financially supported by the Ministry of Science and Higher Education (grant no. NN204 125037).

Open Access This article is distributed under the terms of the Creative Commons Attribution License which permits any use, distribution, and reproduction in any medium, provided the original author(s) and the source are credited.

\section{References}

1. Alsabet M, Grdeń M, Jerkiewicz G (2006) J Electroanal Chem 589:120-127

2. Dall'Antonia LH, Tremiliosi-Filho G, Jerkiewicz G (2001) J Electroanal Chem 502:72-81

3. Tremiliosi-Filho G, Dall'Antonia LH, Jerkiewicz G (2005) J Electroanal Chem 578:1-8

4. Conway BE, Barnett B, Angerstein-Kozlowska H, Tilak BV (1990) J Chem Phys 93:8361-8373

5. Conway BE, Jerkiewicz G (1992) J Electroanal Chem 339:123-146

6. Gilroy D (1976) J Electroanal Chem 71:257-277

7. Alsabet M, Grdeń M, Jerkiewicz G (2011) Electrocatalysis 2:317-330

8. Chao CY, Lin LF, Macdonald DD (1981) J Electrochem Soc 128:1187-1194

9. Fromhold AT, Cook EL (1967) Phys Rev 163:650-664

10. Lawless KR (1974) Rep Prog Phys 37:231-316

11. Smeltzer WW, Young DJ (1975) Prog Solid State Chem 10:17-54

12. Tompkins HG, Augis JA (1981) Oxid Met 16:355-369

13. Łukaszewski M, Czerwiński A (2006) J Electroanal Chem 589:38-45

14. Łukaszewski M, Siwek H, Czerwiński A (2010) J Solid State Electrochem 14:1279-1292

15. Moyes RB, Roberts MW (1977) J Catal 49:216-224

16. Wohlfahrt-Mehrens M, Schenk J, Wilde PM, Abdelmula E, Axmann P, Garche J (2002) J Power Sources 105:182-188

17. Kleperis J, Wójcik G, Czerwiński A, Skowroński J, Kopczyk M, Bełtowska-Brzezińska M (2001) J Solid State Electrochem 5:229-249 
18. Wang S (2006) JOM-J Min Met Mat Soc 58:47-50

19. Davis JR (2000) Nickel, cobalt, and their alloys. ASM, Materials Park

20. Ismail KM, Badawy WA (2000) J Appl Electrochem 30:1303-1311

21. Larramona G, Gutiérrez C (1990) J Electroanal Chem 293:237-252

22. Behl WK, Toni JE (1971) J Electroanal Chem 31:63-75

23. Burke LD, Lyons ME, Murphy OJ (1982) J Electroanal Chem 132:247-261

24. Jayaraman TR, Venkatesan VK, Udupa HVK (1975) Electrochim Acta 20:209-213

25. Sato N, Ohtsuka T (1978) J Electrochem Soc 125:1735-1740

26. Novoselsky IM, Menglisheva NR (1984) Electrochim Acta 29:21-27

27. Foelske A, Strehblow HH (2002) Surf Interface Anal 34:125-129

28. Göhr H, Krüger H (1966) Electrochim Acta 11:835-847

29. Foelske A, Kunze J, Strehblow HH (2004) Surf Sci 554:10-24

30. Santamaria M, Adragna E, Di Quarto F (2005) Electrochem SolidState Lett 8:B12-B15

31. Cowling RD, Riddiford AC (1969) Electrochim Acta 14:981-989

32. Jung H, Alfantazi A (2010) Corrosion 66:035002-03500212

33. Erts D, Ahlberg E, Asbjörnsson J, Olin H, Prikulis J (1998) Appl Phys A-Mat Sci Process 66:S477-S480

34. Grdeń M, Klimek K, Rogulski Z (2009) Electrochem Commun 11:499-503

35. Gomez Meier H, Vilche JR, Arvia AJ (1982) J Electroanal Chem 134:251-272

36. Aledresse A, Alfantazi A (2004) J Mater Sci 39:1523-1526

37. Abd El Rehim SS, El Basosi AA, Osman MM (1993) J Electroanal Chem 348:99-106

38. Correia AN, Machado SAS, Avaca LA (1999) Electrochem Commun 1:600-604

39. Boukamp BA (1986) Solid State lonics 20:31-44

40. Pontinha M, Faty S, Walls MG, Ferreira MGS, Da Cunha Belo M (2006) Corr Sci 48:2971-2986

41. Elumalai P, Vasan HN, Munichandraiah N, Shivashankar SA (2002) J Appl Electrochem 32:1005-1010
42. Jukic A, Piljac J, Metikoš-Hukovic M (2001) J Mol Cat A - Chem 166:293-302

43. Sluyters-Rehbach M (1994) Pure Appl Chem 66:1831-1891

44. Brug GJ, Van Den Eeden ALG, Sluyters-Rehbach M, Sluyters JH (1984) J Electroanal Chem 176:275-295

45. Trasatti S, Petrii OA (1991) Pure Appl Chem 63:711-734

46. Nishizawa T, Ishida K (1983) Bull Alloy Phase Diagr 4:387-390

47. Koneshan S, Rasaiah JC, Lynden-Bell RM, Lee SH (1998) J Phys Chem B 102:4193-4204

48. Norkus E, Vaškelis A (1996) Electroanalysis 8:171-172

49. Ruetschi P, Amlie RF (1966) J Phys Chem 70:718-723

50. Pourbaix M (1966) Atlas of electrochemical equilibria in aqueous solutions. Pergamon, Oxford

51. Bard AJ (ed) (1975) Encyclopedia of electrochemistry of the elements, vol III. CRC, Boca Raton

52. Ohtsuka T, Sato N (1983) J Electroanal Chem 147:167-179

53. Thirsk HR, Harrison JA (1972) A guide to the study of electrode kinetics. Academic, London

54. Scharifker B, Hills G (1983) Electrochim Acta 28:879-889

55. Biesinger MC, Payne BP, Grosvenor AP, Lau LWM, Gerson AR, Smart RSC (2011) Appl Surf Sci 257:2717-2730

56. Gupta RP, Sen SK (1975) Phys Rev B 12:15-19

57. Yang J, Liu H, Martens WN, Frost RL (2010) J Phys Chem C 114:111-119

58. Kim KS (1975) Phys Rev B 11:2177-2185

59. Mclntyre NS, Cook MG (1975) Anal Chem 47:2208-2213

60. Casella IG, Guascito MR (1999) J Electroanal Chem 476:54-63

61. Pyun SI, Hong MH (1992) Electrochim Acta 37:327-332

62. MacDonald DD (2011) Electrochim Acta 56:1761-1772

63. Evans DH (2008) Chem Rev 108:2113-2144

64. Gileadi E (2002) J Electroanal Chem 532:181-189

65. Devanathan MAV (1972) Electrochim Acta 17:1683-1697

66. Armstrong RD, Harrison JA (1969) J Electrochem Soc 116:328 331 